\title{
Comment on "Fluid overload and acute kidney injury in children with tumor lysis syndrome"
}

Arsalan Nadeem ${ }^{1}$ and Satesh Kumar ${ }^{2}$

${ }^{1}$ Allama Iqbal Medical College

${ }^{2}$ Shaheed Mohtarma Benazir Bhutto Medical College

February 1, 2022

\section{Hosted file}

arsalan document.docx available at https://authorea.com/users/458378/articles/554947-commenton-fluid-overload-and-acute-kidney-injury-in-children-with-tumor-lysis-syndrome 